\title{
Examination of Aerofoil Blade Fabricated by Additive Manufacturing Process
}

\author{
K. Kalyani, Dr. Shaik shafee, A. Rajasri, V.SaiManichandra
}

\begin{abstract}
ADDITIVE MANUFACTURING is a method which involves formation of a physical object from a virtual $3 D$ model, usually by numerous successive thin layers of a substance. Traditional design and manufacturing processes have a variety of undesirable limitations in many applications, including expensive tooling, fixtures and assembly of complex parts. However, as in machining, the subtractive manufacturing processes can result in the loss of up to $90 \%$ of the original material block. On considering the accuracy, functionality, high end products, material used and typical layer thickness FDM is the most appropriate and adaptive method for manufacturing the $3 D$ printing objects. The Scope of the work is to design the 4515 airfoil to work without fail under extreme conditions. Analyzing the airfoil at a given inlet speed of $138 \mathrm{~m} / \mathrm{s}$ in ANSYS FLUENT and a structural analysis to determine if it is structurally stable under extreme conditions using ANSYS STRUCTURAL ANALYSIS. In this work, the analysis is carried out by stream of fluid (air) over NACA 4515 Airfoil and its structural analysis. The values obtained are within the desired limits according to NACA, hence the design is structurally safe.
\end{abstract}

Keywords: Additive Manufacturing , Airfoil, FDM , Subtractive manufacturing

\section{INTRODUCTION}

Additive manufacturing or 3D Printing is a method in which a physical object is created from a virtual 3D model, usually by laying down a large number of successive thin layers. By adding layer by layer of materials, a digital object (its CAD representation) into its physical form. There are different techniques for an object being printed in 3D. 3D Printing has two basic innovations: the creation of virtual objects

The various 3D Printing Processes are:

1. Stereolithography (SLA)

2. Digital Light Processing (DLP)

3. Fused deposition Modeling (FDM)

4. Selective Laser Sintering (SLS)

5 . Selective Laser Melting (SLM)

6. Electronic Beam Melting (EBM)

7. Laminated Object Manufacturing (LOM)

8. Binder Jetting (BJ)

9. Material Jetting (MJ)

Fused deposition Modeling (FDM) FDM is a method of

Revised Version Manuscript Received on 16 September, 2019. Venkatapur(V), Ghatkesar(M) Medchal(D), Hyderabad, India

Dr. Shaik shafee, Assistant Professor, Anurag Group of Institutions, Venkatapur(V), Ghatkesar(M) Medchal(D), Hyderabad, India

A. Rajasri, Professor, Anurag Group of Institutions, Venkatapur(V), Ghatkesar(M) Medchal(D), Hyderabad, India

V.SaiManichandra, Student, Anurag Group of Institutions, Venkatapur(V), Ghatkesar(M) Medchal(D), Hyderabad, India
K. Kalyani, Assistant Professor, Anurag Group of Institutions,

3D printing developed by scrott Crump and introduced in the 1980s by Stratasys Ltd. This process involves thermal plastic materials of production quality in order to print their 3D objects. It is known to produce functional prototypes, concept models, and aids to manufacture. It is a technology that can establish precise details and an excellent balance between strength and weight:. Before the FDM printing process starts, the user must use slicing software to divide the 3D CAD data (the 3D model) into multiple layers. The sliced CAD data goes to the printer which creates the layer of artifacts on the construction platform at one time. It does this simply by heating and then extruding through the nozzle and onto the base the thermoplastic filament.

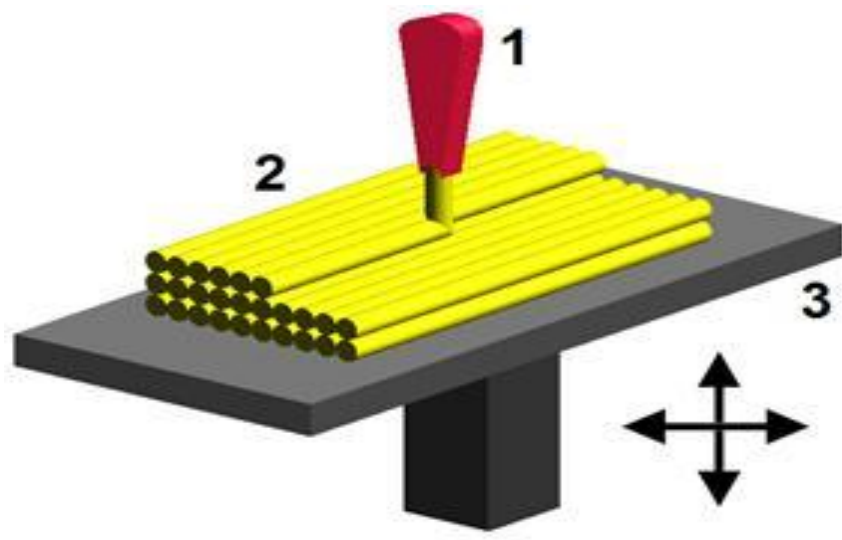

Fig1: Fused Deposition Modeling (FDM) Technology

3D Printing Materials: Since the technology's early days, the materials available for 3D printing have come a long way. There are now a wide variety of different types of materials supplied in various states (powder, fiber, pellets, granules, resin, etc.).

1. Plastics

2. Metals

3. Ceramics

4. Paper

5. Bio Materials

Airfoil

An airfoil (in American English), as seen in the cross-section, is the shape of a wing or blade (of a propeller, rotor, or turbine) The aerodynamic force creates the airfoil-shaped body moving through a liquid. Lift is the perpendicular component of this force to the direction of motion.

\section{Published By:}

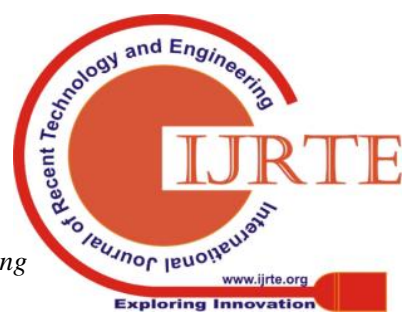


Drag is the parallel portion of the movement direction. Subsonic flight airfoils are characterized by a rounded leading edge, followed by a sharp trailing edge, often with asymmetric upper and lower surface curvature. Hydrofoils are water-like foils of the same type as the working fluid.
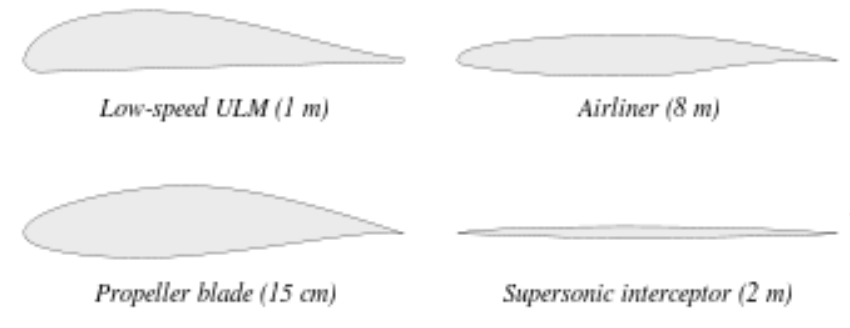

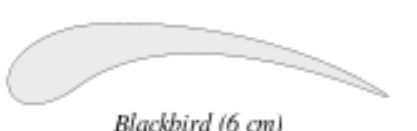

Blackbird $(6 \mathrm{~cm})$

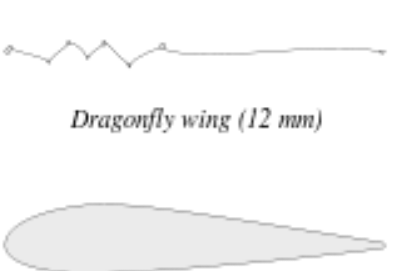

Dolphin flipper fin $(10 \mathrm{~cm})$

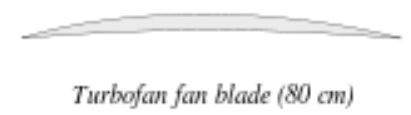

Turbine blade $(8 \mathrm{~cm})$

Sailboat $(3 \mathrm{~m})$
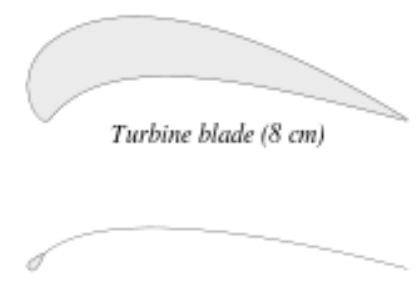

Fig:2. Types of airfoil

An airfoil's lift is primarily the result of its attack angle and shape. The airfoil deflects the oncoming air when positioned at a correct angle, resulting in a pressure on the airfoil in the opposite direction to the deflection known as aerodynamic force, this force can be divided into two components: lift and drag. In order to generate lift, most foil shapes need a positive angle of attack, but cambered airfoils can generate lift at zero angle of attack.

\section{Airfoil Nomenclature}

The various airfoil terms are described below:

- The surface of the suction (a.k.a. upper surface) is usually associated with higher velocity and lower static pressure. The pressure layer (i.e. lower surface) has a constant stress that is comparatively higher than the suction surface. The gradient of pressure between the two surfaces contributes to the lifting force generated by the airfoil.

The airfoil's geometry is defined in various terms:

Leading edge, point of maximum curvature (minimum radius) at the front of the airfoil.

- Likewise, the trailing edge is the highest curvature level at the back of the airfoil.

- The width of the chord is the straight line of the leading and trailing edges. The chord width is the chord line length. This is the airfoil section's reference dimension

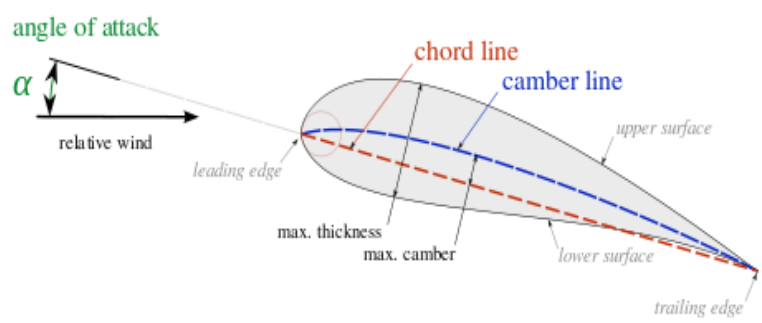

Fig: 3. Airfoil nomenclature

\section{Scope of The Project And Problem Definition}

I. In this project, design of 4515 airfoil is Worked under extreme conditions without failure.

II. To prove this, the airfoil must be tested at a given inlet speed of $138 \mathrm{~m} / \mathrm{s}$ in ANSYS FLUENT and a structural analysis must be carried out to determine whether it is structurally stable under extreme conditions using ANSYS STRUCTURAL ANALYSIS.

III. If the design is safe, the values obtained from the analysis can be used for practical use. We need to analyze the flow of fluid (air) over the NACA 4515 Airfoil and its structural analysis in this project.

\section{DESIGN OF AIR FOIL}

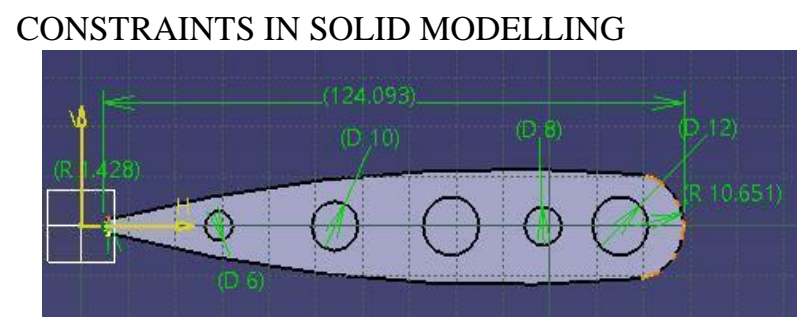

Fig 4.Constraints of Airfoil(front view)

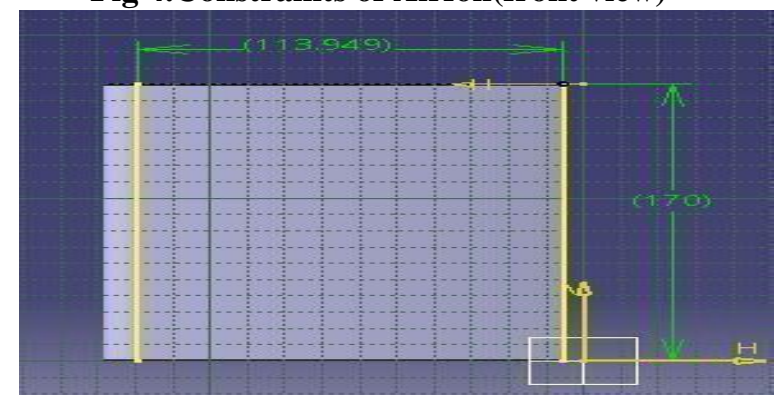

Fig 5. constraints of Airfoil(side view)

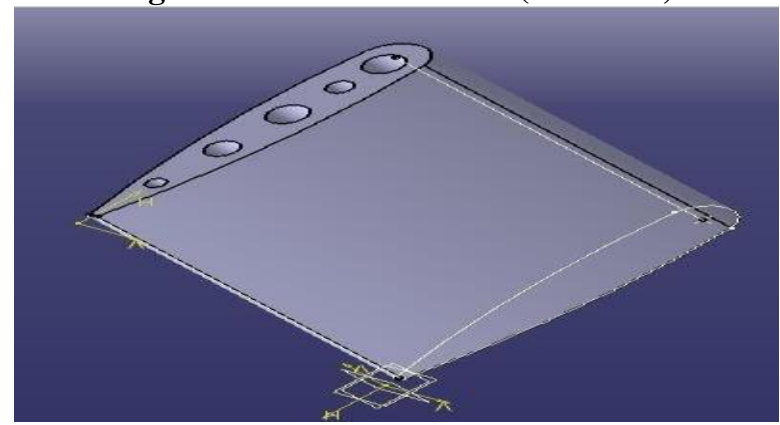

Fig 6. Solid modeling of Airfoil 


\section{PRINTING PROCEDURE}

SOFTWARE Ultimaker Cura is used for Slice the model file of the user into layers and generate a specific g-code for the printer. Once the g-code has been finished, it can be sent to the printer to make the physical object.

APPROACH AND PROCEDURE

Step wise procedure of $3 \mathrm{~d}$ printing parts

Step 1:-Install the curaultimaker software.

Step 2:-Design file should be inserted into cura software. The file should be STL format.

Step 3:-Adjust the design file to the center of the board. Step 4:-We have to convert design file to g code from the tool box in the software.

Step 5:-We have to save and copy in SDHC card (Secure Digital High Capacity card).

Step 6:-The card should be inserted in the 3Dprinting machine.

Step 7:-Set as auto home $>$ read the file $>$ setting flow rate $>$ start printing.

Step.8:-The final product will be developed.

\section{ANALYSIS}

\section{MODELING}

The text file of the coordinate is imported into the development model and the $3 \mathrm{D}$ curve is created using the following coordinates.

Table I: Modelling Approach

\begin{tabular}{|c|c|c|c|c|}
\hline Group & Point & X-cord & Y-cord & Z-cord \\
\hline 1 & 1 & 0 & 0 & -5 \\
\hline 1 & 2 & 5 & 0 & -5 \\
\hline 1 & 3 & 0 & 5 & -5 \\
\hline 1 & 4 & 0 & 0 & -7 \\
\hline 1 & 5 & 5 & 0 & -7 \\
\hline 1 & 6 & 0 & 5 & -7 \\
\hline
\end{tabular}

Material - Aluminum alloy

Compostition-60\% Aluminum 40\% plastic

Table II. Material Properties

\begin{tabular}{|l|l|}
\hline Density & $2770 \mathrm{~kg} \mathrm{~m}-3$ \\
\hline Young's Modulus & $71 \times 109 \mathrm{~Pa}$ \\
\hline Poisson's ratio & 0.33 \\
\hline Tensile yield strength & $28 \times 107 \mathrm{~Pa}$ \\
\hline Tensile ultimate strength & $31 \times 107 \mathrm{~Pa}$ \\
\hline Specific heat & $875 \mathrm{~J} \mathrm{~kg}-1 \mathrm{C}-1$ \\
\hline
\end{tabular}

\section{MESHING}

- The surface in Blue color indicates AirInlet.

- The surface in Red color indicates AirOutlet.

- The white body surface shows the Aerofoil. - The remaining surfaces are symmetrical in four yellow colors and act as a wall showing the entire body, i.e. the aerofoil and the surface.

\section{FLUENTRESULTS}

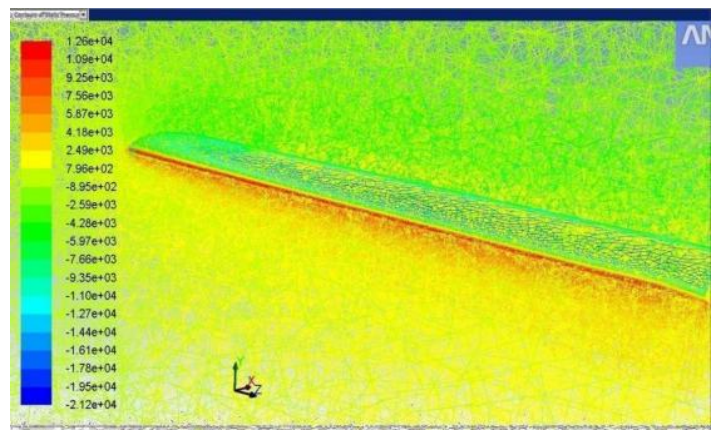

Fig 7. Contours of Static Pressure

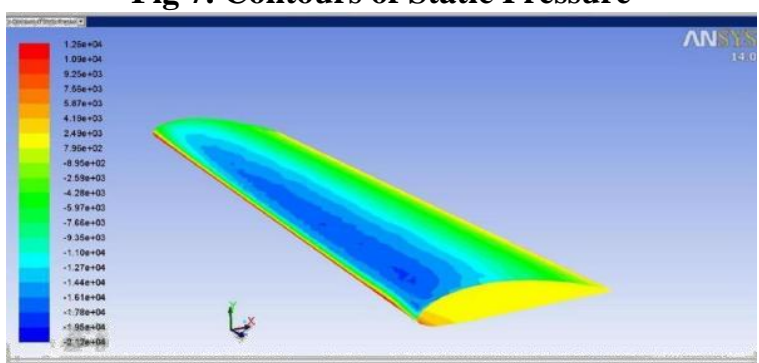

Fig 8. Contours of Static Pressure in Isometric View

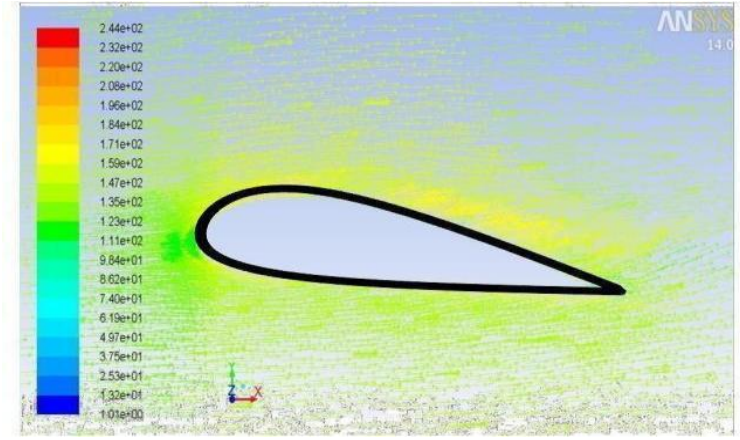

Fig 9. Velocity Vectors

GEOMETRY OF AIRFOIL

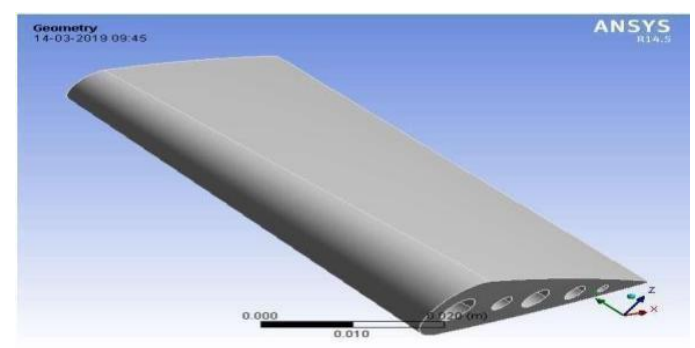

MESH OF AIRFOIL

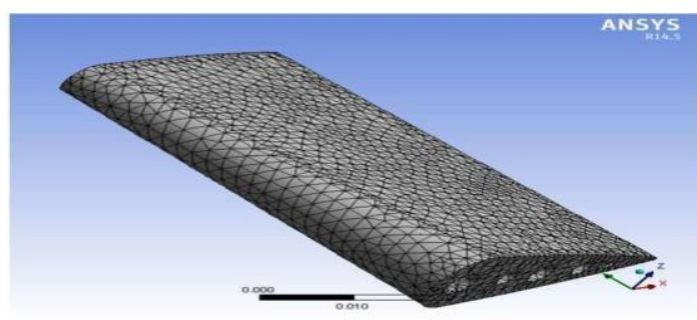

Meshing of airfoil 
Total no. of nodes $=21196$, Total no. of elements $=12112$

Total deformation of air foil under application of $2 \mathrm{~N}$

The maximum deformation of air foil is $1.007 \mathrm{e}-8 \mathrm{~m}$ and minimum deformation starts from $0 \mathrm{~m}$.

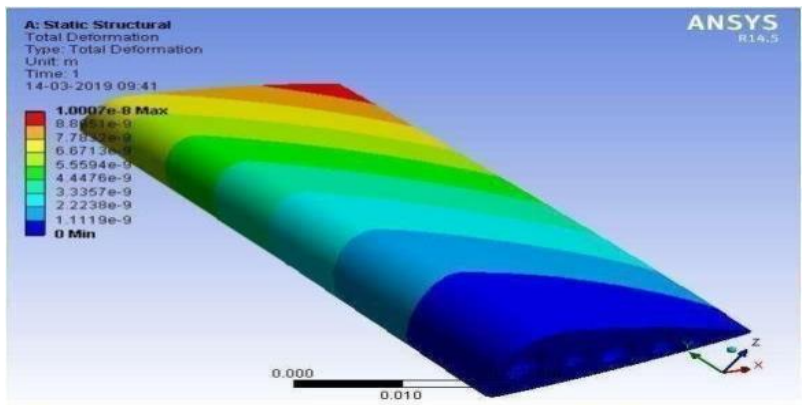

Minimum principal stress of air foil under $2 \mathrm{~N}$ force.

Minimum principal stress (max) 4707.4 pa and Minimum principal stress (min) - 49729 pa.

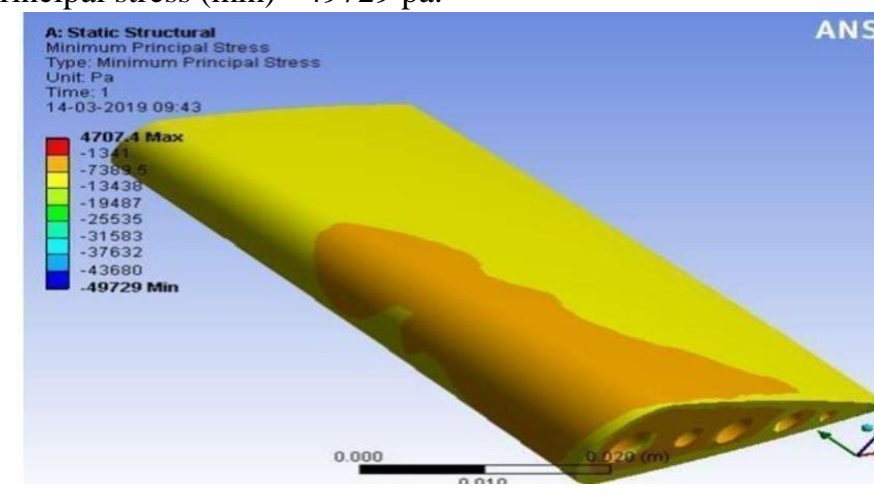

VII. EXPERIMENTAL RESULTS

Rockwell hardness

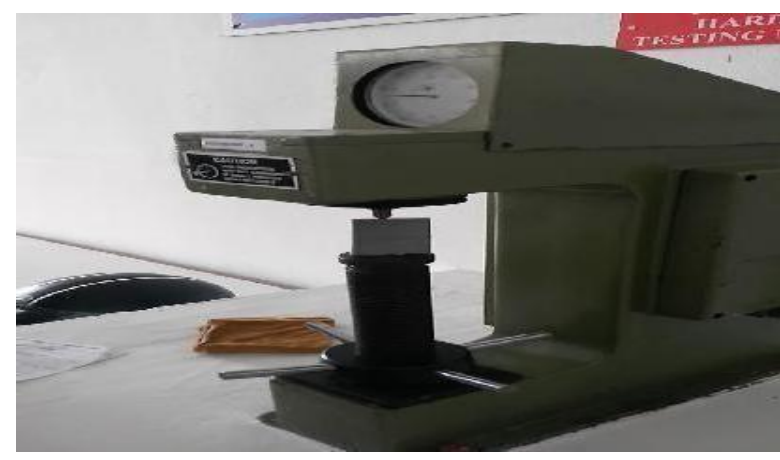

\section{BRINELL HARDNESS TEST}

Hardness Result Analysis

\section{Rockwell Hardness}

Under the application of $100 \mathrm{kgs}$ load on the specimen at 4 different points:

Hardness at 1 st point of airfoil specimen $=58 \mathrm{HRB}$

Hardness at 2nd point of airfoil specimen $=54 \mathrm{HRB}$

Hardness at $3 \mathrm{rd}$ point of airfoil specimen $=58 \mathrm{HRB}$

Hardness at 4th point of airfoil specimen $=58 \mathrm{HRB}$

Hardness of the airfoil specimen $=57 \mathrm{HRB}$
Under the application of $100 \mathrm{kgs}$ load on the specimen at 4 different points:

Hardness at 1 st point of airfoil specimen $\quad=57 \mathrm{HRB}$ Hardness at 2nd point of airfoil specimen $\quad=65 \mathrm{HRB}$ Hardness at 3rd point of airfoil specimen $\quad=68 \mathrm{HRB}$ Hardness at 4th point of airfoil specimen $\quad=58 \mathrm{HRB}$ Hardness of the airfoil specimen $=62$

HRB

\section{UTM Result Analysis}

Area of airfoil $30.4 \mathrm{~mm}^{\wedge} 2$

Length of airfoil $60 \mathrm{~mm}$

Principle load $10 \mathrm{KN}$

Deflection $7 \mathrm{~mm}$

Stress $=$ load/area $328.76 \mathrm{~N} / \mathrm{mm}^{\wedge} 2$

Strain $=$ deformed length/original length 0.117

\section{CONCLUSION}

1. From the study of the fluid flow, it is observed that the maximum value of the static pressure exerted by the air on the air foil surface is $12600 \mathrm{~Pa}$ and that the average velocity of the air from the airfoil surface is $235 \mathrm{~m} / \mathrm{s}$. According to the guidelines of the National Aeronautics Advisory Committee, the value of the static pressure and the velocity magnitude are below the allowable limits and therefore the model is dynamically safe and fluid. In order to determine the structural stability of the design, a static structural analysis is carried out in conjunction with the Workbench system coupling and the values of Equivalent stress, maximum and minimum significant stress, complete deformation, reactions of force and moment are collected.

2. It is found that the maximum value of pressure from losses is $266.11 \mathrm{MPa}$. The maximum main stress is 426.13 $\mathrm{MPa}$, the minimum main pressure is $128.76 \mathrm{MPa}$ and the total deformation by ansys code is $419.33 \mathrm{~mm}$.

3. Through experimentation analysis of airfoil found that the deformed principal stress as $328.76 \mathrm{MPa}$ and hardness of airfoil specimen found to be 57HRB.

4. According to the National Advisory Committee for Aeronautics (NACA), the values obtained are within the acceptable limits.

\section{REFERENCES}

1. Abbott, Ira H.; and von Doenhoff, Albert E.: Theory of Airfoil Sections. Dover, 1952.

2. Theodorsen, Theodore: Theory of Wing Sections of Arbitrary Shape. NACA Report 411, 1931.

3. Theodorsen, Theodore; and Garrick, I.G.: General Potential Theory of Arbitrary Wing Section. NACA Report 452, Dec 2999.

4. Jackson, Ward and Pinkerton: The Characteristics of 78 Related Airfoil Sections from Tests in the Variable-density Wind Tunnel. NACA Report 460, 1933. 
5. Stack, John; and von Doenhoff,Alll: Tests of 16 Related Airfoils at High Speed. NACA Report 492, 1934.

6. Jacobs and Pinkerton: Tests in the Variable-density Wind Tunnel of Related Airfoils Having the Maximum Camber Unusually Far Forward. NACA Report 537, 1935.

7. Betz, A.: Modification of Wing-Section Shape to Assure A Predetermined Change In

8. Pressure Distribution. NACA Technical Memorandum TM-767, December 1934.

9. Anderson, John, D (2007). Fundamentals of Aerodynamics.McGraw-Hill. 